\title{
Bilişsel Esneklik İle Sosyal Medyayı Kullanmaya Yönelik Tutum Arasındaki İlişkinin İncelenmesi
}

\begin{abstract}
Adem PEKER ${ }^{*}$
Fatih ÇUKADAR ${ }^{* *}$

Öz

Bu çalışmanın amacı ergenlerde bilişsel esnekliğin sosyal medyayı kullanmaya yönelik tutum üzerindeki yordayıcı etkisini incelemektir. Araştırmanın çalışma grubunu 309 ortaöğretim öğrencisi oluşturmaktadır. Araştırma verileri Bilişsel Esneklik Ölçeği ve Sosyal Medyaya Yönelik Tutum Ölçeği ile toplanmıştır. Araştırma da yöntem olarak kesitsel tarama modeli kullanılmıştır. Araştırmada verilerin analizi Pearson korelasyon katsayısı ve yapısal eşitlik modeli ile yapılmıştır. Araştırma sonucunda bilişsel esneklik ile sosyal medyayı kullanmaya yönelik tutumun sosyal yetkinlik, paylaşım ihtiyacı ve öğretmenlerle ilişkiler alt boyutları arasında negatif yönde anlamlı ilişkilerin olduğu gözlenirken; sosyal izolasyon boyutuyla anlamlı bir ilişki belirlenmemiştir. Araştırmanın diğer bir sonucunda bilişsel esnekliğin sosyal medyayı kullanmaya yönelik tutumu negatif yönde yordadiğı saptanmıştır.
\end{abstract}

Anahtar Kelimeler: Ergenler, bilişsel esneklik, sosyal medyaya yönelik tutum.

\section{Examination of Relationship Between Cognitive Flexibility and Attitudes Towards The Use of Social Media}

\begin{abstract}
The purpose of this study is to examine the predictive effect of cognitive flexibility on attitudes towards the use of social media in adolescents. The study group was composed of 309 secondary education students. The research data were collected via using the Cognitive Flexibility Scale and the Attitude towards Social Media Scale. In the study, the cross-sectional survey model was used as a method. The analysis of the data was made by using the Pearson correlation coefficient and the structural equality model. As a result of the study, it was observed that while there were significant negative relationships between cognitive flexibility and the social competence, need for sharing and relationships with teachers sub-dimensions of the attitudes towards the social media scale, not a significant relationship was determined in the social isolation dimension. Another result of the study was that cognitive flexibility negatively predicted the attitudes towards the use of social media.
\end{abstract}

Keywords: Cognitive flexibility, social media, adolescents.

\footnotetext{
* Yrd. Doç. Dr., Atatürk Üniversitesi, Kazım Karabekir Eğitim Fakültesi, Eğitim Bilimleri Bölümü, adem.peker@atauni.edu.tr

** Psikolojik Danışman, Ağrı Taşçay Anadolu İHL, fatih_chdr@hotmail.com
} 


\section{GİRIŞ}

Günümüzde sosyal medya; fikir, düşünce, yorum, fotoğraf, video ve yazıların paylaşıldığ 1 bir ortam olarak yoğun kullanılmaktadır (Feyzioğlu, 2016). Sosyal medya sürekli olarak güncellenebilmesi, interaktif olması, paylaşıma açık olması ve ölçülebilir olması sayesinde birçok birey ve kurum tarafından kullanılan en yaygın araç olarak görülmektedir. Bireyler, kişisel bilgilerinin yanında çeşitli resimler, karikatürler, videolar, metinler paylaşabilmekte ve hatta ürün pazarlayıp satışını gerçekleştirebilmektedirler (Bedir, 2016). Bilişim ve iletişim teknolojilerindeki gelişmeler ve uygulamalar insanların birbirleriyle olan iletişimine bir farklılık getirmiştir. Bu farklılıklardan biride sosyal medya kullanımıdır. Akıllı telefonların ortaya çıkması ve her yerden internete ulaşma imkânının olması insanların sosyal medyayı yoğun bir şekilde kullanmalarını sağlamaktadır. Bu durum yeni bir iletişim tarzına geçişin göstergesi olarak kabul edilmektedir.

Sosyal medya teknolojisi giderek büyüyen bir olgudur. Sosyal medya genelde sosyal etkileşimi sağlamak için kullanılır. Bununla birlikte sosyal medya yeni sanal sosyal alanlar yaratmak için tasarım ögeleri de içermektedir. Facebook, LinkedIn, MySpace, YouTube, Wordpress/Blogger, Google+ ve Instagram bu tasar1ma örnekler olarak gösterilebilir (Davis, DeilAmen, Aguilar ve Canche, 2015).

Sosyal medya sanal topluluklar ya da katılımc1ların, birbirleri ile etkileşim toplulukları kurarak ve geliştirerek, bilgi ve fikirleri paylaşmak için kullanılan ağlar olarak belirtilmektedir (Bahrani ve Patel, 2015). Ellison ve Boyd (2007) sosyal medyayı bireylerin başkalarıyla iletişim kurmak için web tabanlı hizmetler olarak nitelendirmektedir.

Yeni oluşan ortamda gençler; kimi hareketli (mobil), kimi günlük hayatlarını stresi ve sıkın- tısından uzaklaşmak ve kendine bağımsız bir alan yaratmaktan, kimi de sosyal etkinliklerini ve hayatlarının neşesini arkadaşları ve dostları ile paylaşmaktan dolayı sosyal medyayı günlük hayatlarının bir parçası haline getirmişlerdir (Düvenci, 2012). Sosyal medyanın kişilerarası iletişimi kolaylaştırması (Çalışır, 2015), eğlence aracı olarak kullanılması (Çemrek, Baykuş ve Özaydın, 2014), bir gruba ait olma duygusu yaşatması (Akçay, 2011) ve bilgiye ulaşmayı sağlaması (Churchill, 2009) bireylerin daha çok sosyal medyayı kullanmasını sağlamaktadır.

Gençlerin yaygın biçimde kullandığı ve düzenli bir şekilde eriştiği sosyal medya platformları hem olumlu hem de olumsuz etkiler göstermektedir. Bu platformların gençlerin özellikle akademik başarı, motivasyon, iletişim, sosyal etkileşim ve yalnızlık gibi farklı değişkenler üzerindeki etkileri; özellikle bireylerin bu siteleri ne amaçla kullandığına bağlı olarak değişmektedir (Tamer, 2014). Bununla birlikte, sosyal medyayı sık kullanan bireylerin sanal ortamda arkadaşlarına karşı saldırganlık davranışlar gösterdikleri belirtilmektedir (Ökte, 2014).

Sosyal medyanın olumsuz kullanımları arasında internet bağımlılı̆̆ı/problemli internet kullanımı gelmektedir. İnternet bağımlılığ1/problemli internet kullanımının krterleri bir günde 6 saatten daha fazla sürmesi, en fazla 3 ay süreyle devam etmesi gelmektedir. Bununla birlikte aşırı internet kullanımının sosyal, çalışma ve iletişim becerilerinde işlev bozukluklarına yol açması ve internet kullanılmadığı zaman uyuma sorunu yaşama, dikkat dağınıklığı, kolay kızma gibi belirtiler gösterilmesi de internet bağımlılığı/problemli internet kullanımı tanısı koşulları arasında yer almaktadır (Li, Li, Wang ve Zhang, 2008). Yapılan araştırmalar özellikle ergenler arasında problemli internet kullanımının (Ayas, 2012; Chou, Condron, ve Belland, 2005; Eroğlu, 2016a; Messias, Castro, 
Saini, Umsan, Peeples, 2011; Young, 2004) yaygin bir sorun olduğunu ortaya koymaktadır.

Bununla birlikte sosyal medyanin olumsuz kullanımının ortaya çıkardığı bir diğer sorununda siber zorbalık davranışların olduğu vurgulanmaktadır. Siber zorbalık bilişim ve iletişim teknolojilerinin e-posta, cep telefonu mesajı ya da internet aracilığıyla tekrarlanan bir şekilde başkalarına zarar vermek amacıyla yapılan davranışlar olarak belirtilmektedir (Ang ve Goh 2010; Arıcak, 2009; Dilmaç, 2009). Araştırmacılar siber zorbalığında (Ayas ve Horzum, 2012; Beran ve Li, 2005; Eroğlu ve Peker, 2015; Eroğlu, Aktepe, Akbaba, Işık ve Özkorumak, 2015; Peker, 2015; Peker ve Eroğlu, 2015; Raskauskas ve Stoltz, 2007; Tanrıkulu, 2015; Ybarra ve Mitchell, 2004) ergenler arasında yoğun olarak görüldüğünü tespit etmiştir.

$\mathrm{Bu}$ araştırmada ele alınan kavramlardan biri de bilişsel esnekliktir. Bilişsel esneklik, bireyin; herhangi bir durumda alternatif seçimleri kullanabilmesini ve yeni durumlara uyum saplayabilmesini işaret etmektedir (Martin ve Anderson, 1998). Bilişsel esneklik bir bilişsel farkındalık kavramının merkezi olarak tanımlanmaktadır (Martin ve Rubin, 1995). Martin ve Anderson (2001) bilişsel esnekliği yüksek olan bireylerin daha çok strateji belirlemeyi kullandıklarını vurgulamıştır.

Bilişsel esnekliğin otoriter anne baba tutumu ve problem çözme becerisi (Bilgin, 2009), iletişim becerileri, duyarl, dikkatli ve anlayışlı olma (Martin ve Anderson, 1998), uyum sağlama yeteneği (Dunleavy ve Martin, 2006), kişilerarası yetkinlikle (Parks, 1994), başa çıkma stratejileri ile (Bedel ve Ulubey, 2015) ilişkili olduğu belirlenmiştir. Bilişsel esnekliğe sahip olan birey, seçeneklerin farkındadır, yeni ve zor durumlarla etkin şekilde baş edebilir, alternatif düşünce ve fikirler üretebilir ve yeni durumlara uyum sağlayabilir (Altunkol, 2011). Toplum içinde yaşayan bireyler birçok sorunla yüz yüze gelmekte ve bu sorunlarını ya öğrenmiş olduğu becerilerle ya da bilişsel düşünce yapılarını kullanarak çözmektedir. Stevens (2009), yüksek bilişsel esnekliğe sahip olmanın, bireylerin problem çözme yeteneğine önemli katk1larının olduğunu ifade etmektedir.

\subsection{Araştırmanın Amacı}

Öğrencilerin sosyal medya kullanım alışkanlıklarını belirlenmek ve sosyal medya araçlarının olumlu-olumsuz etkilerini bilmek birçok sebepten dolayı önemlidir. İnternette geçirdikleri sürenin büyük kısmını sosyal medya araçları oluşturan, kimlik arayışı içinde olan ve kendilerini henüz tanımaya çalışan ergenlik dönemindeki gençler, sosyal medyayı günlük rutinleri arasına yerleştirmiş ve bu durum yaşam tarzlarını da değiştirmiştir (Saraç, 2014).

Sosyal medya kullanımının kişilerarası ilişkileri (Çalışır, 2015, Manen, 2010), ruh sağlı̆̆ını (Doğan ve Tosun, 2016), özel hayatı (Acılar ve Mersin, 2015; Zhang, Sun, Zhu ve Fang 2010) olumsuz etkilediği ve çevrimiçi güvenlik sorunlarına yol açtı̆̆ (Chen ve Michael, 2012) bildirilmektedir. Dolayısıyla ergenlerin sosyal medyayı aşırı bir şekilde kullanmalarını önleyecek çalışmalara ihtiyaç duyulmaktadır. Önleyici çalışmalar kapsamında sosyal medyanın kullanımına yönelik tutumları etkileyecek kavramlardan birinin de bilişsel esneklik olacağ1 düşünülmektedir.

Bilişsel esnekliği fazla olan bireyler, davranışlarının sonucunun başarılı olacağına inanır. Esnek olan birey kişiler arası ilişkilerde kendisini yeterli olarak algılar ve farklı durumlardaki iletişimlerde kendilerini güvende hisseder. Bilişsel esneklik kişilerarası ilişkilerin uyumlu ve olumlu yönde gelişmesini sağlamaktadır. Ayrıca bilişsel esneklik ile yetkinlik beklentisi arasında bir ilişkinin olduğu vurgulanmaktadır (Bilgin, 1999). Yetkinlik beklentisin de bireyin duygu ve düşüncelerine yön vererek bilişi 
etkilediği belirtilmektedir (Sheldon, 1995). Dolayısıyla bilişsel esnekliğin bireylerin davranışlarında rol oynaması sosyal medyayı kullanmaya yönelik tutumunu da etkileyeceği düşünülmektedir. Bu bağlamda, araştırmanın amacı ergenlerde bilişsel esneklik ve sosyal medya kullanımı arasındaki ilişkinin incelenmesi ve bilişsel esnekliğin sosyal medya kullanımını anlamlı düzeyde yordayıp yordamadığının belirlenmesidir.

\section{YÖNTEM}

\subsection{Araştırma Modeli}

Araştırmada bilişsel esneklik ve sosyal medyayı kullanmaya yönelik tutum arasındaki yordayıcı ilişkileri incelemek için kesitsel tarama modeli kullanılmıştır. Kesitsel tarama modelinde değişkenler tek bir ölçümde betimlenir (Büyüköztürk, Çakmak, Akgün, Karadeniz ve Demirel, 2013). Çalışmada ergenlerin bilişsel esneklik ile sosyal medyaya yönelik tutumları arasındaki ilişkiyi açıklamaya yönelik geliştirilen teorik model test edilmektedir.

\subsection{Evren ve Örneklem}

Araştırmanın çalışma evreni 2015-2016 eğitim öğretim yılında Ağrı ilindeki devlet ve özel liselerinden oluşmaktadır. Araştırmanın örneklemi ise Ağrı il merkezinde bulunan tüm okullardan tesadüfi küme örnekleme yöntemi ile belirlenen bir anadolu lisesi, iki meslek lisesi ve bir özel okulda öğrenim gören 309 öğrenciden meydana gelmektedir.

Araştırma örnekleminde yer alan öğrencilerin $170(\% 55)$ tanesi kız, 139 (\%45) tanesi ise erkektir. Öğrencilerin \%26,5'i 9.sinıfta, \%30,4'ü 10. sinıfta, $\% 20,7$ 'si, 11 . sinıfta ve $\% 22$ '3'ü 12 . sinıfta öğrenim görmektedir. Öğrencilerin yaşları 14 ila 19 arasında değişmektedir.

\subsection{Veri Toplama Araçları}

\subsubsection{Kişisel Bilgi Formu}

Araştırmacı tarafından hazırlanmış olup örneklemi oluşturan öğrencilerin; yaş, cinsiyet, sınıf düzeyi ve okul türünden oluşan 4 soruluk formdur.

\subsubsection{Sosyal Medya Tutum Ölçeği}

Öğrencilerin sosyal medyaya ilişkin tutumlarını belirlemek amaciyla Otrar ve Argin (2013) tarafından beşli Likert tipi derecelenme ile geliştirilen ölçek toplam 23 madde şeklindedir. Ölçek paylaşım ihtiyacı, sosyal yetkinlik, sosyal izolasyon ve öğretmenlerle ilişki olmak üzere 4 alt boyuttan oluşmaktadır. Öğrencilerin sosyal medya sitelerinde müzik, yazı, video paylaşması ve paylaşımları konusunda başkalarıyla olan etkileşimi ile ilgili maddeler paylaşım ihtiyacı boyutunda toplanmıştır. Öğrencilerin sosyal medya siteleri aracılığıyla arkadaşlarıyla iletişim kurması ve kendini ifade edebilmesinde yeterli görmesi sosyal yetkinlik boyutuyla ölçülmektedir. Sosyal izolasyon boyutu ise öğrencilerin sosyal medyayı aşırı kullanmalarının sonucu olarak okul başarısı, arkadaşlık ve aile ilişkilerini olumsuz etkilemesiyle ilgilidir. Öğretmenler ile ilişki boyutu da öğrencilerin okul dışında sanal ortamda öğretmenleriyle olan ilişkilerini belirlemektedir. Güvenirlik (iç tutarlık) için yapılan analizlerde ölçeğin tümü için iç tutarlık katsayısının .85; paylaşım ihtiyaC1 için .80, sosyal yetkinlik için .81, sosyal izolasyon için .79 ve öğretmenlerle ilişki için .81 olarak saptanmıştır. Ayrıca ölçeğin test-tekrar test güvenirlik katsayısı ölçeğin tümü için 83; alt boyutlarının da .71 ila .89 arasında değiştiği bulunmuştur. $\mathrm{Bu}$ araştırma kapsamında paylaşım ihtiyacı iç tutarlılık katsayısı .85, sosyal yetkinlik boyutu için iç tutarlılık katsayısı .77, sosyal izolasyon boyutu için iç tutarlılık katsayısı .82 ve öğretmenlerle ilişki boyutu için iç tutarlılık katsayısı .74 olarak saptanmıştır. 


\subsubsection{Bilişsel Esneklik Ölçeği}

Öğrencilerin bilişsel esneklik düzeylerini belirlemek amacıyla Bilgin (2009) tarafından geliştirilen bu ölçek 19 maddeden oluşmaktadır. Ölçek maddeleri olumlu ve olumsuz sıfat çiftlerinden oluşmaktadır. Ölçek bireylerin kendilerini nasıl algıladığını belirlemeyi amaçlamaktadır. Örneğin başarma, yeterlilik, bencillik, azim, kararlılık, korkma, isteklilik ve kendine inanma gibi konularda bireylerin kendilerini nasıl gördükleri ortaya çıarılmaktadır. Ölçekten elde edilen puanlar 19-95 arasındadır. Ölçekten elde edilen puanların artması kişinin bilişsel esnekliğe daha çok yaklaştığını göstermektedir. Ölçek üzerinde yapılan güvenirlik çalışmalarında, ölçeğin bütünü için bulunan iç tutarlılık katsayısının .92; testin tekrarı yöntemiyle bulunan iç tutarlık katsayısının .77, testi yarılama yöntemiyle hesaplanan güvenirlik katsayısının ise .87 olduğu saptanmıştır. Bu araştırma kapsamında ölçeğin iç tutarlılık güvenirlik katsayısı .86 olarak tespit edilmiştir.

\subsection{Verilerin Toplanması}

Araştırmaya başlamadan önce ilgili kurumlardan yasal izin alınmış ve bunun sonucunda uygulama gerçekleştirilmiştir. Araştırma sürecinde öğrencilere katılımın gönüllülük esasına dayandığı bildirilmiştir. Araştırmada kullanılan ölçekler ders saatinde araştırmacı tarafından uygulanmıştır.

\subsection{Verilerin Analizi}

Araştırmada bilişsel esneklik ile sosyal medyayı kullanmaya yönelik tutum arasındaki ilişkiler SPSS 21.00 ve yordayıcı ilişki ise LISREL 8.54 programları aracılığıyla yapılmıştır.

\section{BULGULAR}

Araştırmadan elde edilen veriler sonucunda ergenlerin bilişsel esneklik ve sosyal medyayı kullanmaya yönelik tutum arasındaki ilişkiler ve betimsel istatistiksel sonuçlar Tablo 1'de sunulmuştur.

Tablo 1. Bilişsel Esneklik İle ve Sosyal Medyayı Kullanmaya Yönelik Tutum Arasındaki İlişkilere Yönelik Pearson Korelasyon Analizi ve Betimsel Sonuçlar

\begin{tabular}{llccccc}
\hline & Değişkenler & $\mathbf{1}$ & $\mathbf{2}$ & $\mathbf{3}$ & $\mathbf{4}$ & $\mathbf{5}$ \\
\hline 1 & Bilişsel Esneklik & & & & & \\
2 & Sosyal Yetkinlik & $-.16^{*}$ & 1 & & \\
3 & Paylaşım İhtiyacı & $-.14^{*}$ & $68^{*}$ & 1 & & \\
4 & Öğretmenlerle İlişkiler & $-.13^{*}$ & $.37^{*}$ & $.35^{*}$ & 1 & \\
5 & Sosyal İzolasyon & $-.02^{* *}$ & $-.02^{*}$ & $-.08^{*}$ & $.15^{*}$ & 1 \\
& Çarpıklık & -.63 & .11 & -.55 & .15 & .42 \\
& Basıklık & .33 & -.60 & -.35 & -1.05 & -.75 \\
& $\bar{X}$ & 76.52 & 16.58 & 27.74 & 8.12 & 15.69 \\
& Ss & 11.04 & 5.75 & 7.64 & 3.56 & 6.39 \\
\hline
\end{tabular}

${ }^{*} \mathrm{p}<.05$

${ }^{* *} \mathrm{p}>05$

Tablo 1 incelendiğinde bilişsel esnekliğin sosyal medyaya yönelik tutum ölçeğinin sosyal yetkinlik, paylaşım ihtiyacı ve öğretmenler ile ilişkiler alt boyutları ile negatif yönde ve düşük düzeyde anlamlı ilişkilerin olduğu görülürken; sosyal izolasyon boyutuyla ise anlamlı bir ilişkinin olmadığı saptanmıştır. Ayrıca araştırmada değişkenlerin çarpıklık ve basıklık değerle- 
rinin normallik varsayımını sağladığı görülmektedir.

\section{1 Ölçme Modelinin Test Edilmesi}

Değişkenlere ilişkin yapısal analiz öncesinde araştırmada yer alan değişkenlere ilişkin ölçme modeli incelenmiştir. Örtük değişkenlerle ku- rulan hipotez modelin incelendiği yapısal eşitlik analizi öncesinde modelde tanımlanan örtük değişkenlere ait ölçme modelinin doğrulanıp doğrulanmadığının test edilmesi gerekmektedir. Dolayısıyla öncelikle bilişsel esneklik ve sosyal medyayı kullanmaya yönelik tutuma ilişkin ölçme modeli test edilmiştir. Sonuçlar Tablo 2 de gösterilmiştir.

Tablo 2. Bilişsel Esneklik ve Sosyal Medyaya Yönelik Tutuma İlişkin Ölçme Modeli

\begin{tabular}{|c|c|c|c|c|c|c|c|c|c|}
\hline \multirow[b]{2}{*}{ Maddeler } & \multicolumn{4}{|c|}{ Maddelere İlişkin DFA Değerleri } & \multicolumn{5}{|c|}{ Maddelere İlişkin DFA Değerleri } \\
\hline & Parsela & Parselb & Parselc & $\mathbf{t}$ & SY & Pí & Sí & Öİ & $\mathbf{t}$ \\
\hline 1 & & .46 & & 7.89 & .65 & & & & 11.75 \\
\hline 2 & & & .55 & 9.61 & .58 & & & & 10.18 \\
\hline 3 & & & .51 & 8.75 & & & .43 & & 7.04 \\
\hline 4 & & & .59 & 10.50 & & .54 & & & 9.24 \\
\hline 5 & & .50 & & 8.54 & & .55 & & & 9.42 \\
\hline 6 & .58 & & & 8.33 & & .61 & & & 11.14 \\
\hline 7 & .49 & & & 10.96 & & & .65 & & 13.68 \\
\hline 8 & & .61 & & 9.88 & .54 & & & & 12.15 \\
\hline 9 & & .57 & & 5.11 & & & & .47 & 10.70 \\
\hline 10 & .31 & & & 4.22 & & & & .69 & 13.04 \\
\hline 11 & & & .33 & 4.84 & & & .64 & & 11.88 \\
\hline 12 & .34 & & & 6.34 & & .66 & & & 12.00 \\
\hline 13 & .46 & & & 9.59 & & .60 & & & 12.45 \\
\hline 14 & & & .48 & 7.81 & & & .70 & & 13.66 \\
\hline 15 & & & .60 & 8.14 & & .63 & & & 8.75 \\
\hline 16 & & .54 & & 10.68 & .68 & & & & 9.25 \\
\hline 17 & & .52 & & 9.01 & & .67 & & & 12.48 \\
\hline 18 & .58 & & & 10.25 & .71 & & & & 10.80 \\
\hline 19 & .50 & & & 8.72 & & & & .54 & 9.28 \\
\hline 20 & & & & & .58 & & & & 13.24 \\
\hline 21 & & & & & & .69 & & & 12.96 \\
\hline 22 & & & & & & & .72 & & 13.24 \\
\hline 23 & & & & & & & .74 & & 13.41 \\
\hline
\end{tabular}

Ölçme modeline ilişkin uyum indeksleri Tablo 3 de sunulmuştur.

Tablo 3. Ölçme Modeline İlişkin Uyum İndeksleri

\begin{tabular}{lcccccccc}
\hline Değişkenler & $\chi 2$ & Sd & $\chi 2 /$ Sd & NFI & CFI & SRMR & RFI & RMSEA \\
\hline BES & 415.60 & 142 & 2.93 & .90 & .94 & .072 & .94 & .079 \\
SMYT & 410.45 & 183 & 2.24 & .92 & .96 & .065 & .91 & .064 \\
\hline
\end{tabular}


Tablo 2 ve Tablo 3 incelendiğinde bilişsel esneklik ile sosyal medyaya yönelik tutuma ilişkin doğrulayıcı ölçme modelinin anlamlı olduğu görülmektedir. Bir diğer ifade ile yapısal eşitlik modeli analizi için hem bilişsel esnekliğin hem de sosyal medyaya yönelik tutumun doğrulandığı gözlenmektedir. Ölçme modelinin model uyum indekslerinin anlamlı çıkmasından sonra bilişsel esneklik ve sosyal medya-

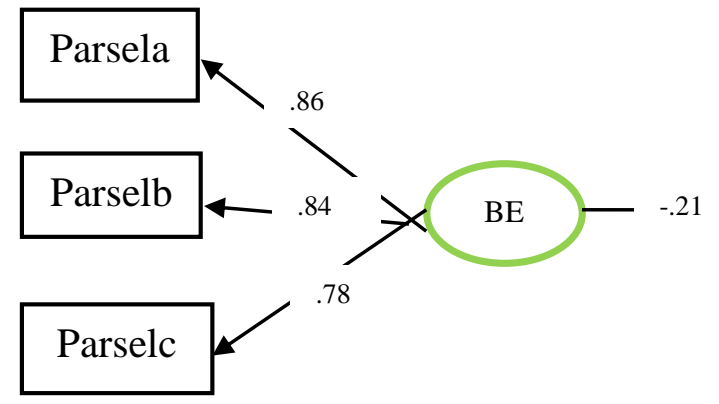

ұ2: 17.07, sd: 8, p: .0294, RMSEA: .061 y1 kullanmaya yönelik tutum için iki örtük değişken belirlenmiştir. Bilişsel esneklik örtük değişkeni (BES) parsela, parselb, parselc gözlenen değişkenleri ile sosyal medyaya yönelik tutum örtük değişkeni ise (SMYT) sosyal yetkinlik, paylaşım ihtiyacı, öğretmenlerle ilişki gözlenen değişkenleri aracılığıyla ölçülmüştür. Yapısal eşitlik modeline ilişkin bulgular Şekil 1 'de verilmiştir.

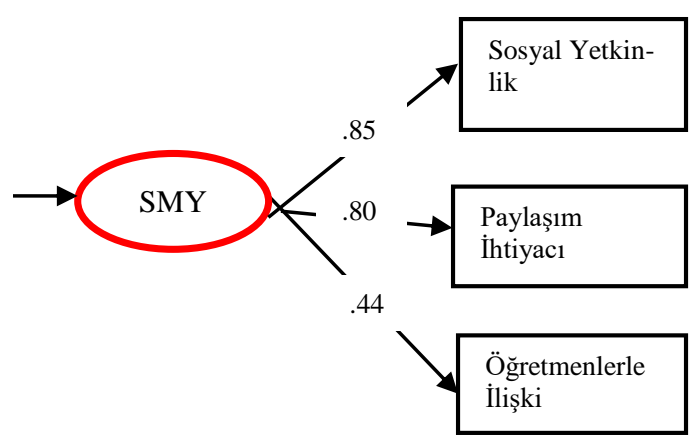

Şekil 1. Bilişsel Esneklik ve Sosyal Medyaya Yönelik Tutum Arasındaki Yapısal Model Analizi

Tablo 4 Yapısal Modele İlişkin t Değerleri

\begin{tabular}{lcccccc}
\hline Değişkenler & Parsela & Parselb & Parselc & SY & Pİ & ÖI \\
\hline BES & 17.44 & 16.98 & 15.34 & & & \\
SMYT & & & & 8.92 & 8.43 & 6.71 \\
\hline
\end{tabular}

Şekil 1 incelendiğinde bilişsel esneklik örtük değişkeninin (BES) sosyal yetkinlik, paylaşım ihtiyacı ve öğretmenlerle ilişki alt boyutlarını kapsayan sosyal medyayı kullanmaya yönelik tutum örtük değişkenini (SMYT) negatif yönde yordadığı gözlenmektedir $(\beta=-.21, \mathrm{t}=-3.06)$. Modelde gösterilen tüm yolların anlamlı olduğu belirlenmiştir $(\chi 2 / \mathrm{sd}=2.76, \mathrm{NNFI}=.97$, $\mathrm{CFI}=.99, \mathrm{IFI}=.99, \mathrm{SRMR}=.026$ ve $\mathrm{RMSEA}=.061$; Kline, 2011). Elde edilen bu bulgu bilişsel esnekliğin sosyal medyayı kullanmaya yönelik tutum üzerinde anlamlı bir etkisinin olduğu şeklinde değerlendirilebilir. Başka bir ifadeyle elde edilen bulgular, ergenlerin bilişsel esnekliğin artmasının sosyal medyayı kullanmaya yönelik tutumları azalttığını ortaya koymaktadır. Bilişsel esnekliğin sosyal medyayı kullanmaya yönelik tutumun \% 4.3'ünü açıkladığı saptanmiştır.

\section{SONUÇ VE TARTIŞMA}

$\mathrm{Bu}$ araştırmada bilişsel esnekliğin sosyal medyayı kullanmaya yönelik tutum üzerindeki yordayıcı rolü incelenmiştir. Araştırmanın sonucunda bilişsel esneklik ile sosyal medyayı kullanmaya yönelik tutumların sosyal yetkinlik, paylaşım ihtiyacı ve öğretmenler ile ilişkiler alt boyutları ile negatif yönde ve düşük düzeyde anlamlı ilişkilerin olduğu belirlenirken; sosyal izolasyon boyutuyla ise anlamlı bir iliş- 
kinin olmadığı ortaya çıkarılmıştır. Araştırmadan elde edilen diğer bir sonuçta bilişsel esnekliğin sosyal medyayı kullanmaya yönelik tutumları negatif düzeyde yordadığı bulunmuştur. Bir diğer ifade ile bilişsel esneklik artıkça sosyal medyayı kullanmaya yönelik tutum azalmaktadır.

Bilişsel esneklik ile sosyal medyaya yönelik tutumun sosyal yetkinlik, paylaşım ihtiyacı ve öğretmenlerle ilişkiler alt boyutları arasında da negatif yönde anlamlı bir ilişki saptanmıştır. Bu çalışmanın ortaya çıkardığı sonuç Bedel ve Ulubey (2015) ile Diril'in (2011) çalışmalarında ortaya çıkan sonuçlarla farklılık göstermektedir. Yine başka bir çalışmada güvenli bağlanma stilinin facebook bağımlılığı negatif, saplantılı bağlanma stilinin de facebook bağımlılığını pozitif bir şekilde yordaması (Eroğlu, 2016b) araştırmanın sonucunu ile benzerlik göstermektedir.

Bu bulgu yüksek bilişsel esnekliğe sahip bireylerin sosyal medyayı kullanmaya ilişkin tutumlarının düştügünü işaret etmektedir. Bilişsel esnekliğin, kişilerarası iletişim becerileriyle pozitif anlamda bir ilişkisinin olduğu belirtilmektedir (Martin ve Rubin, 1994). Aynı zamanda sosyal bilişsel esnekliğe sahip olma, sosyal problem çözme yeteneğini arttırabilmektedir (Stevens, 2009).

Ergenlerin günlük hayattaki ilişkilerinde uyumlu olması, kendini yetkin görmesi, yeni durumlar karşısında çözüm bulabilmesi, olumlu bir bakış açısına sahip olması esnek düşünceler kazanmasına yol açabilmektedir. Bununla birlikte bireyin diğerleriyle iletişiminde kabul görme, beğenilme ve olumlu eleştiriler alma gibi yaşantılar geçirmesi, gerçek hayatta kurduğu ilişkilerde yetkin olmasını, uyum sağlamasını ve girişken olmasını olumlu yönde etkileyebilmektedir. Bu durumda bilişsel esnekliği yüksek olan ergenlerin daha az sosyal medyayı kullanmalarını sağlamaktadır.
Bilişsel esnek bireyler davranışlarının sonucunun olumlu olacağına dair inançları içerdiği için gerçek hayattaki ilişkileri yönetebilmektedirler. Ergenlerin problem yaşadığı kişilerle sorunlarını, doğru başa çıkma stratejilerini kullanarak çözmesi kendisiyle ilgili bilişsel esnekliğinin yüksek olmasına bağlıdır. Kendisine yönelik algısı olumlu olan birey gerçek hayattaki paylaşımlarında hem kendisini sağlıklı bir şekilde ifade edecek hem de başkaları tarafından olumlu geri bildirimler alacaktır. Dolayısıyla bilişsel esnekliği yüksek bireyler arkadaşlık ilişkileri kurup sürdürebilme, duygularını ve düşüncelerini diğer kişilere rahatlıkla aktarabilme konusunda kendini yeterli görebilirler. Bu durum sosyal yetkinlik beklentisini sağlıklı bir şekilde karşılamasını sağlayabilmektedir. Nitekim bu sonuç; bilişsel esneklik ile sosyal yetkinlik arasındaki ilişki olduğunu saptayan Bilgin (2009), Martin ve Rubin (1995), Martin ve Anderson (1998) çalışmalarıyla, benzerlikler taşımaktadır. Bireyin bilişsel yapılara yön veren sosyal yetkinlik bireyin esnek bir bilişsel yapıya sahip olmasına, bunun sonucunda da sosyal medyayı kullanmasına neden olan tutumların azalmasına yol açabilmektedir.

Birçok insan diğer insanlarla iletişimde bulunmak amacıyla arkadaş seçmektedir. Bu arkadaşlar bazen tanımadığımız kişiler bazen okul arkadaşlarımız bazen de öğretmenlerimiz veya aileden herhangi birisi olabilmektedir. İnsanlar kendileri için doğru olacak kişiyi seçebilmesi ve seçtiği bu kişilerle sağlıklı iletişim kurup sürdürmesi için mantıklı karar verme stratejisin devreye girmesi kaçınılmaz olmaktadır. Bilgiç (2015) de araştırmasında mantıklı karar verebilen kişilerin bilişsel esneklik düzeylerinin yüksek olması gerektiğinden bahsetmiştir. Buradan da anlaşılacağı gibi bilişsel esnekliği yüksek olan bireyler mantıklı kararlar vererek olumlu davranışlarda bulunabilecekleri ifade edilebilir. 
Başka bir çalışmada Wiese (2010) yılında, lisans öğrencilerine uyguladığı araştırmasında bilişsel esnekliği yüksek kişilerin benlik saygılarının da pozitif yönde etkilediği sonuca ulaşmıştır. Yüksek benlik saygısına sahip kişiler kendisini sevmesinin yanında herkesi de sevebilmektedir. Başkalarının kendisiyle ilgili algısına çok önem verirler ve yalnız kalmaktan uzak durup onlarla aktif paylaşım içinde olur, onların düşüncelerini önemser. Paylaşım ihtiyacını önemseyen kişiler diğerleri tarafından beğenilmeyi ve memnuniyet duymayı önemseyeceklerdir.

Sosyal medya kullanımının günümüzde hızla artan bir araç olduğu düşünüldüğünde ergenler üzerindeki etkilerinin araştırılması gereken bir konu olmaktadır. Teknolojinin hızla gelişmesi sosyal ağların çeşitlenmesine sebep olmaktadır. Ortaöğretimde öğrenim gören gençlerin okul zamanı dışında sosyal medyaya ulaşabilmesi bu açıdan bakıldığında kolaylaşmaktadır. Bu gençlerin sosyal medyayı ne amaçla kullandığının tam olarak bilinmemesi ve onlar üzerindeki olumsuz etkilerinin en aza indirilmesi de ancak bu araştırmanın daha detaylı incelenmesiyle mümkün olacaktır.

\section{5. ÖNERİLER VE SINIRLILIKLAR}

Araştırma sonucuna göre, yüksek bilişsel esneklik düzeyinin, ergenlerin sosyal medyayı kullanmaya yönelik tutumlarını azalttığı görülmektedir. Dolayısıyla hem öğretmenlerin dersler hem de okul psikolojik danışmanının uygulamalar ve etkinlikler yoluyla öğrencilerin bilişsel esnekliğini artırabilirler. Ayrıca düşük bilişsel esnekliğe sahip öğrenciler belirlenerek, bilişsel esneklik düzeylerini artıracak uygulamalara yapılabilir. Günümüzde çeşitli sosyal ağlar ortaya çıkmaktadır. Hem bu sosyal ağların kullanılması hem de bağımlılık düzeyine ulaşmaması için öğrencilere ve ailelerine sosyal medyanın nasıl kullanılması gerektiği konusunda bilgi verilerek farkındalık kazanmaları sağlanabilir. Bununla birlikte öğrencilerin sosyal medyayı kullanım amaçları, bu amaçların gerçekçi olup olmadığı ve gerçek yaşamla ne kadar tutarlı olduğu araştırılabilir. Araştırmanın, Ağrı ilindeki lise öğrencileriyle gerçekleştirilmiş olup farklı illerdeki örneklem gruplarıyla araştırma yapılabilir. Aynı zamanda lise öğrencileri üzerinde uygulanması dolayısıyla ortaokul öğrencileri gibi küçük yaş gruplarına veya üniversite öğrencileri gibi de büyük yaş gruplarına uygulanarak farklılıklar incelenebilir.

\section{Kaynakça}

Acılar, A. ve Mersin, S. (2015). Üniversite öğrencilerinin facebook kullanımı ile mahremiyet kaygısı arasındaki ilişki. Elektronik Sosyal Bilimler Dergisi, 14(54), 103-114.

Akçay, H. (2011). Kullanımlar ve doyumlar yaklaşımı bağlamında sosyal medya kullanımı: Gümüşhane üniversitesi üzerine bir araştırma. İletişim Kuram ve Araştırma Dergisi, 33, 138-161.

Ang, R.P. ve Goh, D.H. (2010). Cyberbullying among adolescents: The role of affective and cognitive empathy, and gender. Child Psychiatry and Human Development, 41, 387-397.

Arıcak, O.T. (2009). Psychiatric symptomatology as a predictor of cyberbullying among university students. Eurasian Journal of Educational Research, 34,167-184.

Ayas, T. (2012). The relationship between internet and computer game addiction level and shyness among high school students. educational sciences: Theory E Practice, 12(2), 632-636. 
Ayas, T. ve Horzum, M. B. (2012). İlköğretim öğrencilerinin sanal zorba ve mağdur olma durumu. retim Online, 11(2), 369-380.

Altunkol, F. (2011). Üniversite öğrencilerinin bilişsel esneklikleri ile algılanan stres düzeyleri arasındaki ilişkinin incelenmesi. Yayınlanmamış yüksek lisans tezi. Çukurova Üniversitesi Sosyal Bilimler Enstitüsü, Adana.

Bahrani, A.A. ve Patel, D. (2015). Incorporating twitter, instagram, and facebook in economics classrooms. The Journal of Economic Education, 46(1), 56-67.

Bedel, A. ve Ulubey, E. (2015). Ergenlerde başa çıkma stratejilerini açıklamada bilişsel esnekliğin rolü. Elektronik Sosyal Bilimler Dergisi, 14(55), 291-300.

Bedir, A. (2016). Sosyal medya kullanımının üniversite öğrencilerinin akademik başarllarına ve tutumlarına etkisi. Yayımlanmamış yüksek lisans tezi. Atatürk Üniversitesi Eğitim Bilimleri Enstitüsü, Erzurum.

Beran, T. ve Li, Q. (2005). Cyber harassment: A study of new method for an old behavior. Journal of Educational Computing Research, 32(3), 265-277.

Bilgiç, R. (2015). Ergenlerin cinsiyet ve öğrenim kademesi düzeylerine göre bilişsel esneklik düzeyleri ile karar stratejileri arasındaki ilişkinin incelenmesi. Yayınlanmamış yüksek lisans tezi. Çukurova Üniversitesi, Adana.

Bilgin, M. (2009). Bilişsel esnekliği yordayan bazı değişkenler. Çukurova Üniversitesi Eğitim Fakültesi Dergisi, 3(36), 142-157.

Bilgin. M. (1999). Ergenlere yönelik sosyal yetkinlik beklentisi ölçeği geliştirme çalışması. Türk Psikolojik Danışma ve Rehberlik Dergisi. 2, 12,7-15.

Büyüköztürk, Ş., Çakmak, E., Akgün, Ö., Karadeniz, Ş. ve Demirel, F. (2013). Bilimsel araştırma yöntemleri. Ankara: PegemA Yayınları

Chen, X. ve Michael, K. (2012). Privacy issues and solutions in social network sites. Technology and Society Magazine, 31(4), 43-53.

Chou, C., Condron, L. ve Belland, J.C. (2005). A review of the research on internet addiction. Educational Psychology Review, 17(4), 363-388.

Churchill, D. (2009). Educational applications of Web 2.0: Using blogs to support teaching and learning. British Journal of Educational Technology, 40, 179-83.

Çalışır, G. (2015). Kişilerarası iletişimde kullanılan bir araç olarak sosyal medya: Gümüşhane üniversitesi iletişim fakültesi öğrencilerine yönelik bir araştırma. E-Journal of New World Sciences Academy, 10 (3), 115-144.

Çemrek, F., Baykuş, H. ve Özaydın, Ö. (2014). Sosyal medya kullanım ve davranışlarının kullanımlar ve doyumlar yaklaşımı bağlamında incelenmesi: Eskişehir Osmangazi Üniversitesi örneği. Alphanumeric Journal, 2(2), 61-76.

Davis, C.H.F., Deil-Amen, R., Aguilar, C.R. ve Canche, M.S.G. (2015). Social media, higher education, and community colleges: A research synthesis and implications for the study of two-year institutions. Community College Journal of Research and Practice, 39, 409-422.

Dilmaç, B. (2009). Psychological needs as a predictor of cyber bullying: A preliminary report on college students. Educational Sciences: Theory and Practice, 9, 1291-1325. 
Drill, A. (2011). Lise öğrencilerinin bilişsel esneklik düzeylerinin sosyo-demografik değişkenler ve öfke düzeyi ile öfke ifade tarzları arasındaki ilişki açısından incelenmesi. Yayınlanmamış yüksek lisans tezi. Çukurova Üniversitesi, Adana.

Doğan, U. ve Tosun, N.İ. (2016). Lise öğrencilerinde problemli akıllı telefon kullanımının sosyal kayg1 ve sosyal ağların kullanımına aracılık etkisi. Adıyaman Üniversitesi Sosyal Bilimler Enstitüsü Dergisi, 8 (22), 100-128.

Dunleavy, K. ve Martin, M. (2006). A convergent validity study of the decision-making collaboration scale. American Journal of Psychology, 8 (2), 339-344.

Düvenci, A. (2012). A $\breve{g}$ neslinin internet kullanımı üzerindeki sosyal medya etkisinin sosyal sapma yaklaşımı ile incelenmesi. Yayımlanmamış doktora tezi. Marmara Üniversitesi Sosyal Bilimler Enstitüsü, İstanbul.

Ellison, N. B. ve Boyd, D. M. (2007). Social network sites: Definition, history and scholarship. Journal of Computer Mediated Communication, 12(1), 210-230.

Eroğlu, Y. (2016a). Üniversite öğrencilerinde problemli internet kullanımı: İlişkisel-karşılıklı bağımlı benlik kurgusu ve dürtüselliğin yordama güçleri. Turkish Studies International Periodical for the Languages, Literature and History of Turkish or Turkic Volume 11/3, 1091-1114.

Eroğlu, Y. (2016b). Interrelationship between attachment styles and facebook addiction. Journal of Education and Training Studies, 4 (1), 150-160.

Eroğlu, Y., Aktepe, E., Akbaba, S., Işık, A. ve Özkorumak, E. (2015). Siber zorbalık ve mağduriyetin yaygınlığının ve risk faktörlerinin incelenmesi. Ĕ̆itim ve Bilim, 40(177), 93-107.

Eroğlu, Y. ve Peker, A. (2015). Ergenlerde akran ilişkileri ile siber zorbalık statüleri arasındaki ilişkinin incelenmesi. Turkish Studies 10(11), 593-606.

Feyzioğlu, B.İ. (2016). Eğitimde sosyal medyanın kullanılmasına ilişkin okul yöneticileri ve öğretmenlerin görüşleri. Yayımlanmamış yüksek lisan tezi. Afyon Kocatepe Üniversitesi Fen Bilimleri Enstitüsü, Afyon.

Kline, R. B. (2011). Principles and practice of structural equation modeling. New York: The Guilford Press

Li, L., Li, G. Y., Wang, Y. Y. ve Zhang, S. Y. (2008). The effects of residential hospital treatment on 48 internet addiction patients. Journal of Psychiatry, 21, 356-360.

Manen, M. V. (2010). The pedagogy of momus technologies: Facebook, privacy, and online intimacy. Qualitative Health Research, 20(8), 1023-1032.

Martin, M. M. ve Anderson, C. M. (2001). The relationship between cognitive flexibility and affinityseeking strategies. Advances in Psychological Research, 4, 69-76.

Martin, M. M. ve Anderson, C. M. (1998). The cognitive flexibility scale: Three validity studies. Communication Repots, 11, 1-9.

Martin, M. M. ve Rubin, R. B. (1995). A new measure of cognitive flexibility. Psychological Reports, 76, 623-626.

Messias, E., Castro, J., Saini, A., Umsan, M. ve Peeples, D. (2011). Sadness, suicide, and their association with video game and internet overuse among teens: Results from the Youth Risk Behavior Survey 2007 and 2009. Suicide and Life-Threatening Behavior, 41(2), 1-9. 
Ortar, M. ve Argın, S. (2015). Öğrencilerin sosyal medyaya ilişkin tutumlarını belirlemeye yönelik bir ölçek geliştirme çalışması. Ĕ̆̉itim ve Öğretim Araştırmaları Dergisi, 4 (1), 391-403.

Ökte, A. (2014). Öğrencilerin zorbalık eğ ilimleri ile sosyal medyaya yönelik tutumları arasındaki ilişkinin incelenmesi. Yayımlanmamış yüksek lisans tezi. Yeditepe Üniversitesi. Sosyal Bilimler Enstitüsü, İstanbul.

Parks, M. R. (1994). Communication competence and interpersonal control. In M. L. Knapp \& G. R. Miller (Eds.), Handbook of interpersonal communication (pp. 589-620). CA: Sage: Beverly Hills.

Peker, A. (2015). Ortaokul öğrencilerinin siber zorbalık statülerini yordayan risk faktörlerinin incelenmesi. Ĕ̆itim ve Bilim, 40(181), 57-75.

Peker, A. ve Eroğlu, Y. (2015). Ergenlerde algılanan sosyal destek ve siber zorbalığa eğilim arasındaki ilişkiler: Arkadaştan ve öğretmenden algılanan sosyal desteğin aracı rolü. Turkish Studies, 10 (3), 759-778.

Raskauskas, J. ve Stoltz, A.D. (2007). Involvement in traditional and electronic bullying among adolescents. Developmental Psychology, 43, 564-575.

Saraç, N. (2014). 8. sını öğrencilerinin benlik saygıları ile sosyal medyaya yönelik tutumları arasındaki ilişki (Beykoz İlçesi Örneği). Yayınlanmamış yüksek lisans tezi. Yeditepe Üniversitesi, Eğitim Bilimleri Enstitüsü, İstanbul.

Sheldon, B. (1995). Cognitive behavioral therapy. London: Routledge.

Stevens, A. D. (2009). Social problem-solving and cognitive flexibility: Relations to social skills and problem behavior of at-risk young children. Unpublished doctoral thesis. Seattle Pacific University.

Tamer, N. (2014). Ergenlerin teknolojik zorbalık algıları ve buna yönelik teknolojik zorbalık farkındalı̆̆ı ĕgitimi: Pilot uygulama. Yayınlanmamış yüksek lisans tezi. Bahçeşehir Üniversitesi, Eğitim Bilimleri Enstitüsü, İstanbul.

Tanrıkulu, T. (2015). Cyberbullying and basic needs: A predictive study within the framework of choice theory. Anthropologist, 20(3), 573-583.

Wiese, S. L. (2010). The downside of self-esteem stability: Does stability impede flexibility. Unpublished master's dissertation, Florida Atlantic University Boca Raton, Florida.

Ybarra, M. ve Mitchell, K. J. (2004). Online aggressor/targets, aggressors, and targets: A comparison of associated youth characteristics. Journal of Child Psychology and Psychiatry, 45, 1308-1316.

Young K.S. (2004). Internet addiction: A new clinical phenomenon and its consequences, American Behavioral Scientis, 48(4), 402-415.

Zhang, C., Sun, J., Zhu, X., Fang, Y. (2010). Privacy and security for online social networks. Challenges and Opportunities. IEEE Network, 24(4), 13-18. 


\section{Extended Summary}

\section{Purpose}

Developments and practices in information and communication technologies have made a difference in humans' communication with one another. One of these differences is media use. Smart phones' having shown up and the possibility of accessing the Internet from everywhere help people use the social media intensively. This situation is accepted as the transition to a new style of communication.

Social media technology is a gradually growing phenomenon. Social media is generally used to achieve social interaction. However, social media includes design components to create new virtual social domains as well. Facebook, LinkedIn, MySpace, YouTube, WordPress/Blogger, Google+ and Instagram can be shown as examples for this design (Davis, Deil-Amen, Aguilar and Canche, 2015).

When it is considered that cognitive flexibility and social media have an important place in adolescents' lives, it is obvious that the place to make a contribution to solving communication problems which individuals live in their lives healthily is again the social media environment where they can solve them by getting close to other people. In this context, the purpose of this study is to examine the relationship between cognitive flexibility and social media use in adolescents and determine if cognitive flexibility predicts social media use at a significant level.

\section{Methods}

In the study, in order to examine predictive relationships between cognitive flexibility and attitude towards the use of social media, the cross-sectional survey model was used. The study group was composed of 309 secondary education students from four different high schools in Ağr1 in the 2015-2016 educational year. Of the participants, 170 (55\%) were female and 139 (45\%) were male. Of the students, $26,5 \%$ were the 9 th grade, $30,4 \%$ were the 10 th grade, $20,7 \%$ were the 11 th grade and 22 ' $3 \%$ were the 12 th grade students. The students' attitudes towards the social media were determined by using a scale of 23 items developed by Otrar and Argin (2013) and their cognitive flexibility levels by using a scale of 19 items developed by Bilgin (2009). In the study, the relationships between cognitive flexibility and attitudes towards social media were analyzed by using the SPSS 21.00 program and the predictive relationship by using the LISREL 8.54 program.

\section{Results}

As a result of the study, it was determined that while there were significant negative relationships at low level between cognitive flexibility and the social competence, need for sharing and relationships with teachers sub-dimensions of the attitudes towards the use of social media scale, there was not a significant relationship in the social isolation dimension. Another result of the study was that the latent variable of cognitive flexibility (CF) negatively predicted the latent variable of the attitudes towards the social media (ATSM) covering the social competence, need for sharing and relationships with teachers sub-dimensions $(\beta=-.21, t=-3.05)$. It was determined that all the routes shown in the model were meaningful $(\chi 2 / \mathrm{sd}=2.76, \mathrm{NNFI}=.91, \mathrm{CFI}=.92, \mathrm{IFI}=.92, \mathrm{SRMR}=.071$ and $\mathrm{RMSEA}=.077 ;$ Kline, 2011). It was determined that cognitive flexibility accounted for $4,3 \%$ of the attitudes towards the social media. 


\section{Discussion}

A significant negative relationship was determined between cognitive flexibility and the social competence, need for sharing and relationships with teachers sub-dimensions of the attitudes towards the social media scale. The result which this study revealed shows similarity to the ones found in the studies carried out by Bedel and Ulubey (2015) and Diril (2011). This finding can be evaluated to mean that individuals with high cognitive flexibility both establish more careful and positive relationships with their friends, teachers and newly-met people over social media and do healthier sharing with them. People's statements, comments about others over social networks might lead them to develop a perception mechanism about themselves after a while. If people develop their thoughts about themselves positively, the support mechanism which they perceive will be positive, too. Individuals with a positive selfperception will both express themselves healthily in his/her social sharing and receive positive feedback from others.

This study includes some limitations. Since the study was carried out with the high school students in Ağrl, it is limited to them. For this reason, it is important to repeat the study with sample groups from different cities in terms of generalizability of the findings. At the same time, differences can be examined by applying the study to younger age groups like secondary school students or to older age groups like university students.

The measurement model was created using parcels for each latent construct in the models tested in this study. Item parceling is a method that normalizes the distribution of observed variables and increases the reliability of these indicators. Indicators as parcels were created for each latent variable by rankordering items by the size of the item-total correlation and summing sets of items to obtain equivalent indicators for those constructs(Kuzucu \& Şimşek, 2013). 